\title{
PRELIMINARY REPORT ON EVALUATION OF POTENTIAL ELUANTS FOR NON-ACID ELUTION OF CESIUM FROM RESORCINOL-FORMALDEHYDE RESIN
}

SEPTEMBER 2010

Savannah River National Laboratory Savannah River Nuclear Solutions Aiken, SC 29808

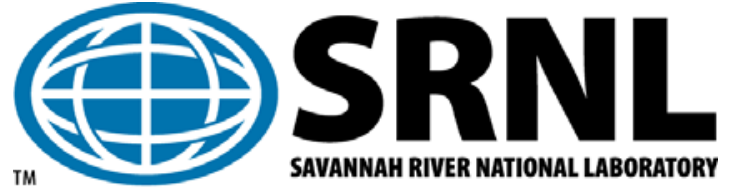




\section{DISCLAIMER}

This work was prepared under an agreement with and funded by the U.S. Government. Neither the U. S. Government or its employees, nor any of its contractors, subcontractors or their employees, makes any express or implied:

1. Warranty or assumes any legal liability for the accuracy, completeness, or for the use or results of such use of any information, product, or process disclosed; or

2. Representation that such use or results of such use would not infringe privately owned rights; or

3. Endorsement or recommendation of any specifically identified commercial product, process, or service.

Any views and opinions of authors expressed in this work do not necessarily state or reflect those of the United States Government, or its contractors, or subcontractors.

This document was prepared in conjunction with work accomplished under Contract No. DE-AC09-08SR22470 with the U.S. Department of Energy.

\section{Printed in the United States of America}

Prepared For

U.S. Department of Energy 
Key Words:

Non-acid elution

Sorption

Resorcinol-formaldehyde resin

Cesium

Ion exchange

Small-column ion exchange (SCIX)

Batch contact method

Eluants

Retention: Permanent

Key References:

Task Technical and Quality Assurance Plan for Non-Acid Elution of Cesium From

Resorcinol-Formaldehyde Resin: SRNL-TR2009-00314, Rev. 0, August 2009

\title{
PRELIMINARY REPORT ON EVALUATION OF POTENTIAL ELUANTS FOR NON-ACID ELUTION OF CESIUM FROM RESORCINOL-FORMALDEHYDE RESIN
}

\author{
K. Adu-Wusu, SRNL/E\&CPT \\ F. M. Pennebaker, SRNL/E\&CPT
}

Issue Date: September 2010 


\section{REVIEWS AND APPROVALS}

Author:

K. Adu-Wusu, Author, SRNL/E\&CPT Research Programs

Date

\section{Reviewer:}

C. A. Nash, Technical Reviewer, SRNL/E\&CPT Research Programs

Date

SRNL Management:

F. M. Pennebaker, Manager SRNL/E\&CPT Research Programs

Date

S. L. Marra, Manager SRNL/E\&CPT Research Programs

Date

Hanford Representative:

D. H. Shuford, Manager, Hanford Tank Farm

Date 
TABLE OF CONTENTS

LIST OF TABLES ......................................................................................................................... IV

LIST OF FIGURES ............................................................................................................................IV

LIST OF ACRONYMS ................................................................................................................ V

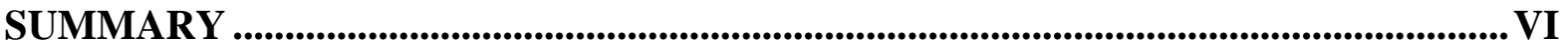

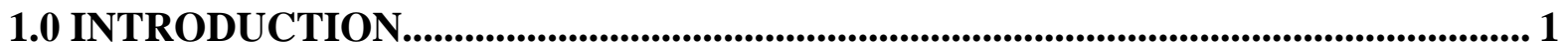

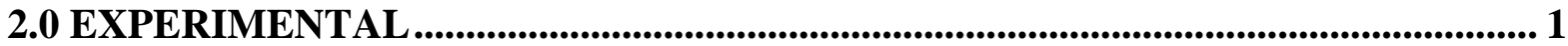

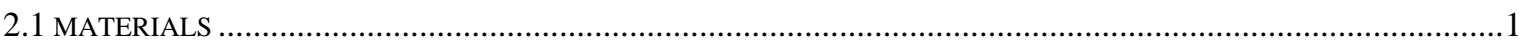

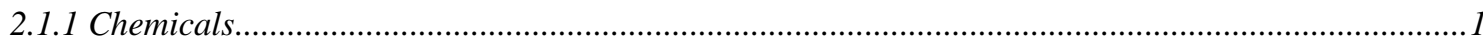

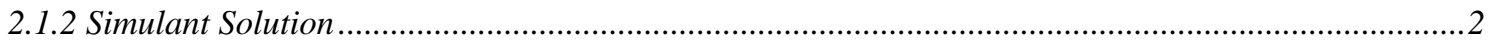

2.1.3 Resin Preconditioning and F-Factor Determination ................................................................2

2.1.4 Preparation of Eluant/Other Relevant Solutions ......................................................................4

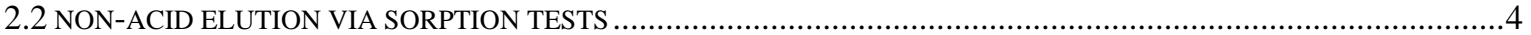

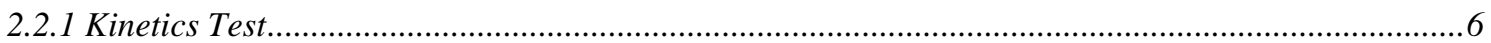

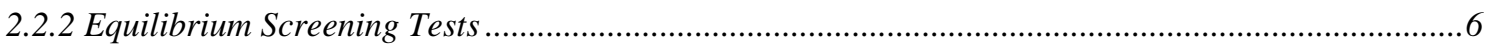

3.0 RESULTS AND DISCUSSION ............................................................................. 6

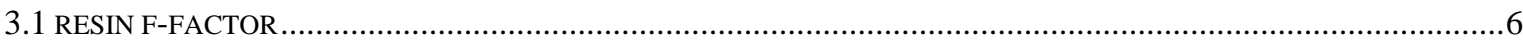

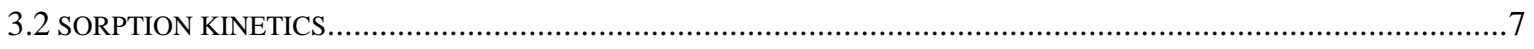

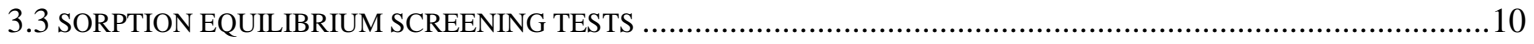

4.0 CONCLUSIONS ......................................................................................................................... 20

5.0 PATH FORWARD ............................................................................................................... 20

6.0 REFERENCES...................................................................................................................... 21 


\section{LIST OF TABLES}

TABle 1. Concentration of the Constituents In SRS TANK 2F SuPERnate Simulant. . 3

TABLE 2. CESIUM SORPTION KINETICS FOR $\sim 2 \mathrm{M}$ AMMONIUM CARBONATE AND SRF RESIN AT $25{ }^{\circ} \mathrm{C}$.

TABle 3. DATA FOR CESIUM SORPTION EqUILIBRIUM SCREENING TESTS AT $25^{\circ} \mathrm{C}-$ SETS 1,2 $\& 3$.

TABLE 4. WHAT-IF SCENARIOS FOR INITIAL CESIUM CONCENTRATION (SORPTION EQUILIBRIUM SCREENING TEST - SET 1)................................................................. 16

TABLE 5. WHAT-IF SCENARIOS FOR INITIAL CESIUM CONCENTRATION (SORPTION EQUILIBRIUM SCREENING TEST - SET 2). ................................................................. 17

TABLE 6. WHAT-IF SCENARIOS FOR INITIAL CESIUM CONCENTRATION (SORPTION EQUILIBRIUM SCREENING TEST - SET 3)............................................................. 18

TABLE 7. WHAT-IF SCENARIOS FOR INITIAL CESIUM CONCENTRATION (SORPTION KINETICS TEST).

TABLE 8. RANKING OF ELUANTS FROM THE CESIUM SORPTION EQUILIBRIUM SCREENING TESTS (SETS 1, 2 \& 3).

\section{LIST OF FIGURES}

Figure 1. CESIUM SORPTION Kinetics FOR 2 M AMmonium CARbonate SOLUTION AND SRF RESIN. 


\section{LIST OF ACRONYMS}

$\begin{array}{ll}\mathrm{C}_{\mathrm{f}} & \text { Final cesium concentration } \\ \mathrm{C}_{\mathrm{i}} & \text { Initial cesium concentration } \\ \mathrm{CMC} & \text { Critical micelle concentration } \\ \mathrm{dC} & \begin{array}{l}\text { Change in solution cesium concentration i.e., initial minus final cesium } \\ \text { concentration }\end{array} \\ \text { DSA } & \text { Documented Safety Analysis } \\ \text { E\&CPT } & \text { Environmental \& Chemical Process Technology } \\ \text { F-Factor } & \text { Ratio of the vacuum-dried mass to the damp mass of the resin } \\ \text { ICP-MS } & \text { Inductively Coupled Plasma-Mass Spectrometry } \\ \mathrm{K}_{\mathrm{d}} & \text { Sorption distribution coefficient } \\ \text { LAW } & \text { Low-activity waste } \\ \mathrm{S} & \text { Cesium sorbed } \\ \text { SCIX } & \text { Small-column ion exchange } \\ \text { sRF } & \text { spherical resorcinol-formaldehyde } \\ \text { SRNL } & \text { Savannah River National Laboratory } \\ \text { SRS } & \text { Savannah River Site } \\ \mathrm{T}_{\mathrm{i}} & \text { Target initial cesium concentration } \\ \text { WAC } & \text { Weak acid cation } \\ \text { WTP } & \text { Waste Treatment and Immobilization Plant }\end{array}$




\section{SUMMARY}

Small-column ion exchange (SCIX) units installed in high-level waste tanks to remove Cs137 from highly alkaline salt solutions are among the waste treatment plans in the DOEcomplex. Spherical Resorcinol-Formaldehyde (sRF) is the ion exchange resin selected for use in the Hanford Waste Treatment and Immobilization Plant (WTP). It is also the primary ion exchange material under consideration for SCIX at the Hanford site. The elution step of the multi-step ion exchange process is typically done with $0.5 \mathrm{M}$ nitric acid. An acid eluant is a potential hazard in the event of a spill, leak, etc. because the high-level waste tanks are made of carbon steel. Corrosion and associated structural damage may ensue.

Studies are ongoing to explore non-acid elution as an alternative. Batch contact sorption equilibrium screening tests have been conducted with 36 potential non-acid eluants. The sorption tests involve equilibrating each cesium-containing eluant solution with the sRF resin for 48 hours at $25{ }^{\circ} \mathrm{C}$ in a shaker oven. In the sorption tests, an eluant is deemed to have a high cesium elution potential if it minimizes cesium sorption onto the sRF resin. The top candidates (based on lowest cesium sorption distribution coefficients) include ammonium carbonate, ammonium carbonate/ammonium hydroxide, ammonium bicarbonate, rubidium carbonate, ammonium acetate, ammonium acetate/ammonium hydroxide, ammonium bicarbonate/ammonium hydroxide, calcium chloride, and magnesium chloride.

The next phase of testing for this work will focus on the following down selected eluants: Ammonium carbonate, ammonium acetate, calcium acetate, magnesium acetate, nitric acid, and ammonium hydroxide. The next testing phase is a confirmation of the elution ability of the selected eluants. It will mimic a typical sRF cesium ion exchange process i.e., sorption or loading, caustic wash, water rinse, and elution via batch contact sorption and quasi column caustic wash/water rinse/elution.

Due to corrosion concerns, calcium acetate and magnesium acetate will be tested instead of calcium chloride and magnesium chloride respectively. Nitric acid is for benchmarking since it is the baseline sRF eluant. The information at hand indicates ammonium hydroxide, while a weak base, may hold promise as an effective eluant. Hence, its inclusion among the eluants to be studied despite the fact that it was not tested as a stand-alone eluant earlier. 


\subsection{INTRODUCTION}

Plans are underway to use small-column ion exchange (SCIX) units installed in high-level waste tanks to remove Cs-137 from highly alkaline salt solutions. Spherical ResorcinolFormaldehyde (sRF) ion exchange resin, known for its high selectivity for cesium in highly alkaline radioactive wastes, is the baseline material under consideration for the Hanford site. ${ }^{1}$ It is a weak acid cation (WAC) exchange resin and as a result has a high affinity for hydrogen ions. Therefore, it is easily eluted with acid solutions. Nitric acid is used most frequently.

Tanks containing highly alkaline radioactive waste are made of carbon steel. Use of an acid eluant may pose a hazard to the tank integrity (corrosion and associated structural damage) in the event of a spill, leak, etc. It will also impact the Documented Safety Analysis (DSA) in that a Criticality Safety Evaluation Report will be required because of potential effect on fissile material "form" and "distribution". 2 In addition, criticality limits for transfers from non-tank farm facilities (if the supplemental pretreatment facility is so designated) require $\mathrm{pH}$ of source waste to be at least $8 .^{3}$

A non-acid eluant may be a viable alternative. It will eliminate the need for special acid handling requirements within the tank farms. Further, non-acid elution will fit in quite well if low-activity waste (LAW) processing is initiated at the Hanford site prior to the completion of the Waste Treatment and Immobilization Plant (WTP). ${ }^{4}$ This is because early LAW treatment will require design and implementation of interim pretreatment operations (either in-tank or near-tank) at the tank farm.

The objective of this study was to evaluate (via batch contact sorption screening tests) the cesium elution potential from sRF resin using non-acid compounds identified in an earlier literature review. ${ }^{5}$ Specifically, cesium sorption distribution coefficients $\left(K_{d}\right)$ on sRF resin from cesium-containing eluants were measured. A lower cesium $K_{d}$ indicates high elution potential. The work was done per the test plan issued earlier. ${ }^{6}$

\subsection{EXPERIMENTAL}

\subsection{MATERIALS}

\subsubsection{Chemicals}

All the chemicals used were reagent grade. They were from various sources or manufacturers. The list of chemicals and their manufacturers are as follows.

1. Ammonium acetate - Fisher Scientific, Pittsburgh, Pennsylvania.

2. Ammonium bicarbonate - MP Biomedicals, Solon, Ohio.

3. Ammonium carbonate - Fisher Scientific, Pittsburgh, Pennsylvania.

4. Ammonium hydroxide - LabChem Inc., Pittsburgh, Pennsylvania

5. Calcium chloride - Alfa Aesar, Ward Hill, Massachusetts.

6. Cesium nitrate - GFS Chemicals, Inc., Columbus, Ohio 
7. Hexadecyltrimethylammonium chloride - Fisher Scientific, Pittsburgh, Pennsylvania.

8. Lithium chloride - Fisher Scientific, Pittsburgh, Pennsylvania.

9. Lithium hydroxide - Fisher Scientific, Pittsburgh, Pennsylvania.

10. Lithium sulfate - Sigma-Aldrich Corporation, St. Louis, Missouri.

11. Magnesium chloride hexahydrate - Fisher Scientific, Pittsburgh, Pennsylvania.

12. Magnesium sulfate - Fisher Scientific, Pittsburgh, Pennsylvania.

13. Potassium bicarbonate - Fisher Scientific, Pittsburgh, Pennsylvania.

14. Potassium carbonate - Fisher Scientific, Pittsburgh, Pennsylvania.

15. Potassium hydroxide - Fisher Scientific, Pittsburgh, Pennsylvania.

16. Rubidium carbonate - Sigma-Aldrich Corporation, St. Louis, Missouri.

17. Sodium bicarbonate - Fisher Scientific, Pittsburgh, Pennsylvania.

18. Sodium carbonate - Fisher Scientific, Pittsburgh, Pennsylvania.

19. Sodium hydroxide - Fisher Scientific, Pittsburgh, Pennsylvania.

20. Tetrabutylphosphonium hydroxide - Sigma-Aldrich Corporation, St. Louis, Missouri.

21. Tetramethylammonium chloride - Sigma-Aldrich Corporation, St. Louis, Missouri.

22. Tetramethylammonium hydroxide - Sigma-Aldrich Corporation, St. Louis, Missouri.

23. Tetramethylphosphonium bromide - Sigma-Aldrich Corporation, St. Louis, Missouri.

\subsubsection{Simulant Solution}

A portion of the supernate simulant (SRS Tank 2F) that was used for the SCIX testing was used for these tests. ${ }^{7,8}$ Table 1 gives the target and measured concentrations of the constituents in the Tank $2 \mathrm{~F}$ supernate simulant. ${ }^{7}$

This supernate simulant will be referred to as "as-received or regular" Tank 2F simulant solution. The concentration of cesium $(2.45 \mathrm{mg} / \mathrm{L}$, see Table 2$)$ in the as-received simulant measured during the kinetics test is close to the measured value in Table 1 . The concentration of cesium in a portion of the as-received simulant was increased (by adding non-radioactive cesium nitrate) to match the cesium concentration $(500 \mathrm{mg} / \mathrm{L}$ nominal) in the eluants. This is referred to as "spiked" Tank 2F simulant solution later in the report.

The as-received simulant was used to check the quality of the resin in terms degradation and the spiked simulant was used to establish a benchmark for the eluant tests.

\subsubsection{Resin Preconditioning and F-Factor Determination}

About 400 grams of moist H-form resin (Lot \# 5E-370/641) was used for the study. The resin was manufactured by Microbeads AS in Skedsmokorset, Norway. The resin is stable as long as it is stored in deionized water with an inert gas headspace. Even though this batch of resin is five years old, periodic checks via testing on its quality (regarding degradation) indicate its quality is still intact. ${ }^{7,9-11}$ The resin was preconditioned using protocols developed by Savannah River National Laboratory (SRNL) in 2004. ${ }^{12,13}$

Resin preconditioning involves taking the resin through deionized water, $\mathrm{NaOH}(1 \mathrm{M})$, deionized water, $\mathrm{HNO}_{3}(0.5 \mathrm{M})$, and deionized water steps at room temperature. The preconditioning protocol was extended by two additional steps [i.e., $\mathrm{NaOH}(1 \mathrm{M})$ and deionized water] in order to bring the resin to the Na-form. It was more appropriate to have the resin in Na-form for the tests because the resin (being a weak acid cation resin) has a 
strong affinity for the hydrogen ion. The resin is in $\mathrm{Cs} / \mathrm{K} / \mathrm{Rb} / \mathrm{Na}$-form (with $\mathrm{Na}$ being the predominant cation) in the actual column elution ion exchange step. There is an instance in the literature when cesium sorption or loading onto $\mathrm{H}$-form resin was marginal compared to loading onto $\mathrm{Na}$-form resin. ${ }^{14}$

Table 1. Concentration of the Constituents in SRS Tank 2F Supernate Simulant.

\begin{tabular}{|c|c|c|}
\hline Analyte & Target Concentration, mg/L (M) & Measured Concentration, mg/L (M) \\
\hline Free $\mathrm{OH}^{-}$ & $12,920(0.76)$ & $13,600(0.80)$ \\
\hline $\mathrm{CO}_{3}^{2-}$ & $7,800(0.13)$ & $\mathrm{nm}$ \\
\hline $\mathrm{NO}_{2}^{-}$ & $6,854(0.149)$ & $7,850(0.171)$ \\
\hline $\mathrm{NO}_{3}^{-}$ & $259,800(4.19)$ & $306,800(4.95)$ \\
\hline $\mathrm{PO}_{4}^{3-}$ & $475(0.005)$ & $<1,000(<0.011)$ \\
\hline $\mathrm{SO}_{4}{ }^{2-}$ & $3,070(0.032)$ & $3,170(0.033)$ \\
\hline $\mathrm{Cl}^{-}$ & $106(0.003)$ & $<250(<0.007)$ \\
\hline $\mathrm{F}^{-}$ & $55(0.003)$ & $<250(<0.013)$ \\
\hline $\mathrm{Br}^{-}$ & $\mathrm{n} / \mathrm{a}$ & $<250(<0.003)$ \\
\hline$(\mathrm{HCOO})^{-}$ & $\mathrm{n} / \mathrm{a}$ & $<250(<0.006)$ \\
\hline$\left(\mathrm{C}_{2} \mathrm{O}_{4}\right)^{2-}$ & $\mathrm{n} / \mathrm{a}$ & $540(<0.006)$ \\
\hline $\mathrm{Al}$ & $6,980(0.26)$ & $8,600(0.32)$ \\
\hline $\mathrm{B}$ & $\mathrm{n} / \mathrm{a}$ & $<1.19\left(<1.10 \times 10^{-4}\right)$ \\
\hline $\mathrm{Ba}$ & $\mathrm{n} / \mathrm{a}$ & $<0.28\left(<2.0 \times 10^{-6}\right)$ \\
\hline $\mathrm{Ca}$ & $\mathrm{n} / \mathrm{a}$ & $<1.56\left(<2.50 \times 10^{-8}\right)$ \\
\hline $\mathrm{Cd}$ & $\mathrm{n} / \mathrm{a}$ & $<0.353\left(<3.10 \times 10^{-6}\right)$ \\
\hline $\mathrm{Cr}$ & $\mathrm{n} / \mathrm{a}$ & $<0.38\left(<7.30 \times 10^{-6}\right)$ \\
\hline Cs & $2.26\left(1.70 \times 10^{-5}\right)$ & $2.25\left(1.69 \times 10^{-5}\right)$ \\
\hline $\mathrm{Cu}$ & $\mathrm{n} / \mathrm{a}$ & $<1.4\left(<2.20 \times 10^{-5}\right)$ \\
\hline $\mathrm{Fe}$ & $\mathrm{n} / \mathrm{a}$ & $<2.0\left(<3.58 \times 10^{-5}\right)$ \\
\hline $\mathrm{K}$ & $274(0.007)$ & $296(0.0076)$ \\
\hline $\mathrm{Li}$ & $\mathrm{n} / \mathrm{a}$ & $<0.45\left(<1.44 \times 10^{-4}\right)$ \\
\hline Mo & $\mathrm{n} / \mathrm{a}$ & $<2.53\left(<2.64 \times 10^{-5}\right)$ \\
\hline $\mathrm{Na}$ & $137,900(6.00)$ & $144,000(6.26 \mathrm{M})$ \\
\hline $\mathrm{Ni}$ & $\mathrm{n} / \mathrm{a}$ & $<1.07\left(<1.82 \times 10^{-5}\right)$ \\
\hline $\mathrm{P}$ & $384(0.012)$ & $164(0.005)$ \\
\hline $\mathrm{Pb}$ & $\mathrm{n} / \mathrm{a}$ & $<3.02\left(<1.46 \times 10^{-5}\right)$ \\
\hline $\mathrm{Rb}$ & $0.535\left(6.30 \times 10^{-6}\right)$ & $0.0098\left(1.0 \times 10^{-7}\right)$ \\
\hline $\mathrm{S}$ & $1,023(0.032)$ & $1,170(0.036)$ \\
\hline $\mathrm{Si}$ & $\mathrm{n} / \mathrm{a}$ & $<7.7\left(<2.74 \times 10^{-4}\right)$ \\
\hline $\mathrm{Zn}$ & $\mathrm{n} / \mathrm{a}$ & $<1.1\left(<1.68 \times 10^{-5}\right)$ \\
\hline $\mathrm{pH}$ & 14 & 14 \\
\hline
\end{tabular}

n/a - not applicable

nm - not measured 
The F-factor of the damp or moist preconditioned Na-form resin was determined by drying roughly 0.5 -gram samples to a constant weight under vacuum at $50{ }^{\circ} \mathrm{C}$. The F-Factor is the solids fraction remaining after the vacuum drying. The F-factor was measured in duplicate. The F-factor of the damp preconditioned H-form resin was also measured in a similar manner prior to the extended steps mentioned earlier.

Damp resin is defined as a preconditioned resin whose water has been drained to the lowest content practical through use of filter pads and minimal vacuum drying at ambient temperature such that it will be devoid of free liquid (i.e., surface or excess water).

\subsubsection{Preparation of Eluant/Other Relevant Solutions}

Desired concentrations of the solution of each eluant and other relevant compounds (e.g., $\mathrm{NaOH}$, and $\mathrm{HNO}_{3}$ ) were prepared. Each preparation involved weighing a predetermined amount of the eluant chemical(s) and adding it/them to a required volume of deionized water followed by stirring at room temperature. Cesium in the form of cesium nitrate was added to each eluant solution when the dissolution of the eluant compound(s) was complete. It was again followed by stirring until the cesium nitrate completely dissolved.

A few of the eluants, namely, ammonium bicarbonate, ammonium carbonate, lithium hydroxide, and potassium bicarbonate, did not completely dissolve. Hence, they were filtered under vacuum using $0.45 \mu \mathrm{m}$ nylon Nalgene (Rochester, New York) filter units prior to the addition of the cesium nitrate. The undissolved constituents seem to be impurities because the amounts of the compounds added were below their respective solubilities at room temperature. An approximate symbol precedes the concentration of the eluants that did not completely dissolve (see Tables 4-8).

To avoid unnecessary delays and excessive analytical costs, confirmatory analysis of the prepared solutions was not done. The associated risks are low because the exact concentration of the eluants was not critical for the screening tests.

\subsection{NON-ACID ELUTION VIA SORPTION TESTS}

As mentioned earlier, the cesium-elution ability (from the sRF resin) of the eluants was assessed via batch contact sorption tests. Both the cesium and the cation of the eluant compete for the soprtion sites on the sRF resin. The extent to which cesium sorption is suppressed describes the relative elution strength of the eluant. Cesium $\mathrm{K}_{\mathrm{d}}$ 's were measured and used as a determinant of the elution potential of the eluants.

This elution via sorption approach (as a screening tool) is in line with the cardinal ion exchange principle i.e., ion exchange is by and large a reversible process much like the chemical reactions that occur in solutions. It is also in line with the known elutability characteristic of the sRF resin. Generally in ion exchange, the resin exchanges its ions for ions in solution as long as conditions are favorable. The terms sorption/loading, elution, or regeneration are outcomes or expectations based on process manipulations. The resin's characteristic function is based on the same principle mentioned above regardless of whether 
it is sorption/loading, elution, or regeneration. In other words, the resin does not care or know whether it is sorption/loading, elution, or regeneration.

The equation below depicts a typical ion exchange reversible reaction where ion $\mathrm{A}$ on the resin (denoted by underline) is exchanged for ion B in solution.

$$
\underline{\mathrm{RA}}^{+}+\mathrm{B}^{+} \mathrm{Y}^{-} \Leftrightarrow \underline{\mathrm{RB}^{+}}+\mathrm{AY}^{-}
$$

It must be emphasized that equilibrium can be approached from either direction.

This elution via sorption approach was used at SRS in 1980. The batch contact cesium sorption results were in agreement with cesium column loading and elution results. The paper did not mention whether it is a validated method. ${ }^{15}$ The preceding discussion clearly indicates a validation is not necessary.

The batch contact test procedure described below pertains to both the kinetics and the equilibrium screening tests (see sections 2.2.1 and 2.2.2). The specifics for each test are given in their respective sections.

A batch contact test entails the following. Twelve milliliters of cesium-containing eluant (or simulant) solution with known concentrations of eluant and cesium was added to 1.5840 grams of damp sRF resin in 20-mL polypropylene vials equipped with polypropylene screw caps (Chasma Scientific, Inc., Cambridge, Massachusetts). The sRF resin (of known Ffactor) was in the Na-form. The resin-eluant mixture was equilibrated for a predetermined time. See Tables 2 and 3 in the results and discussion section for all the concentrations, equilibration times, and volume of solution/mass of resin ratios (i.e., phase ratios).

To limit or avoid resin degradation, the headspace of the vial containing the resin-eluant mixture was purged with nitrogen prior to capping. The equilibration was done in a Refrigerated Incubator Shaker (model Innova ${ }^{\circledR}$ 4230, New Brunswick Scientific Company, Inc., Edison, New Jersey) equipped with test tube or vial racks at a shaking speed of $200 \mathrm{rpm}$ and a temperature of $25 \pm 0.1{ }^{\circ} \mathrm{C}$. A Mettler-Toledo (Columbus, Ohio) analytical balance (model AE 240) with an accuracy of $\pm 0.0001 \mathrm{~g}$ was used to weigh the materials.

Control tests were conducted along with and in the same manner as the sorption test described above. A control is a cesium-containing eluant solution (or simulant) solution with no solids or resin. It is utilized to determine the initial solution concentration of the desired constituent (i.e., cesium). All the sorption tests were conducted in duplicate.

At the end of the predetermined equilibration period, about 3-mL sample of the solution was withdrawn using a syringe-syringe filter $(0.45 \mu \mathrm{m}$ nylon; Whatman, Inc., Florham Park, New Jersey) assembly equipped with stainless steel needle (Popper \& Sons, Inc., New Hyde Park, New York) for analysis of cesium by Inductively Coupled Plasma-Mass Spectrometry (ICPMS). The sampling vials were 7-mL polypropylene vials equipped with polypropylene screw caps (Chasma Scientific, Inc., Cambridge, Massachusetts). The amount of cesium sorbed was determined from the initial and final concentrations of cesium in solution. 
The temperature of the resin-solution mixture was monitored periodically during the tests using a standard laboratory organic-filled glass thermometer to measure the temperature of deionized water in a polypropylene vial placed in the Refrigerated Incubator Shaker along with the testing vials. The average temperature of the bottled water was $25.7 \pm 0.6{ }^{\circ} \mathrm{C}$ throughout the entire testing period. Note that the water-filled vial was taken out of the oven before the temperature was quickly measured. As a result, the temperature was a little higher because of the relatively high room temperature.

\subsubsection{Kinetics Test}

The sorption kinetics test was conducted to determine the sorption equilibrium time needed for the equilibrium screening tests (see next subsection). The sorption method described earlier was followed. Sampling (one per specified equilibration time per vial) occurred at the end of 4, 7, 24, 48, 72, 96, and 192 hours.

Ammonium carbonate was used for the kinetics test. Its selection was based on its fairly wide use as a successfully cesium-eluant from other resins in both plant operation setting and laboratory tests. $^{14-21}$

To instill confidence or give validity to the eluant testing data, a sorption test was performed along with the kinetics test using the as-received Tank $2 \mathrm{~F}$ simulant (cesium concentration = $2.24 \mathrm{mg} / \mathrm{L}$ ) mentioned earlier in subsection 2.1.2. This is because the cesium sorption data from a previous test using the same simulant are available for comparison. ${ }^{7}$ Comparable results also reaffirm the quality of the resin in terms of degradation even though the resin's quality is not in doubt.

In addition, another sorption test was conducted with the spiked Tank $2 \mathrm{~F}$ simulant (cesium concentration $=458 \mathrm{mg} / \mathrm{L}$ ). As mentioned previously, the cesium concentration in the spiked Tank 2F simulant was the same as the cesium concentration in the eluants. The cesium sorption data of the spiked Tank 2F simulant served as a benchmark in the evaluation of the eluant cesium sorption data as discussed later in subsection 3.2. The equilibration period for both tests was 192 hours.

\subsubsection{Equilibrium Screening Tests}

The sorption equilibrium screening tests commenced once the equilibrium time was determined from the sorption kinetics test. Again, the batch contact method described earlier was followed.

\subsection{RESULTS AND DISCUSSION}

\subsection{RESIN F-FACTOR}

The F-factor of the preconditioned Na-form resin equals 0.3157 [percent relative standard deviation $(\mathrm{RSD})=1.08$ ]. The F-factor of the preconditioned $\mathrm{H}$-form resin prior to conversion to $\mathrm{Na}$-form equals 0.2893 (percent RSD $=3.46$ ). The ratio of $\mathrm{Na}$-form/H-form resin equals 1.28 . 
All the data given below are on a Na-form basis. The ratio or H-form resin F-factor is provided to facilitate meaningful comparison with other sRF cesium sorption data.

\subsection{SORPTION KINETICS}

Figure 1 shows a plot of the cesium sorption kinetics data for $2 \mathrm{M}$ ammonium carbonate solution and sRF resin at $25{ }^{\circ} \mathrm{C}$ in terms of cesium concentration in solution versus equilibration time.

The cesium sorption is fast initially and flattens around 24 to 48 hours, then rises between 48 and 72 hours and finally tapers off as sorption proceeds. Similar cesium sorption kinetics behavior (dip/rise) has been observed for sRF in several simulants. ${ }^{22,23}$ The dip/rise is within the error $( \pm 20 \%)$ in the analysis (see error bars on Figure 1$)$. The fluctuations are relatively small. The average ratio of the 48-hour concentration to each of the concentrations of the last three data points (i.e., 72, 96, and 192 hours) is 0.87. In addition, the average of the concentrations at 7, 24, 48, 72, 96, and 192 hours is $289 \mathrm{mg} / \mathrm{L}$ with percent RSD of 8 . For all practical purposes, equilibrium is attained in 48 hours. Hence, 48-hour equilibration time was used for the sorption equilibrium screening tests (see next subsection).

Table 2 gives the cesium sorption kinetics data for $\sim 2 \mathrm{M}$ ammonium carbonate solution along with the data for cesium sorption from spiked Tank $2 \mathrm{~F}$ simulant solution and as-received or regular Tank 2F simulant solution at 192 hours of equilibration.

The sorption distribution coefficient, $\mathrm{K}_{\mathrm{d}}$, was determined with the equation below.

$$
\mathrm{K}_{\mathrm{d}}=\left[\left(\mathrm{C}_{\mathrm{i}}-\mathrm{C}_{\mathrm{f}}\right) \mathrm{V}\right] /\left[\mathrm{mFC}_{\mathrm{f}}\right]
$$

$\mathrm{C}_{\mathrm{i}}$ is initial cesium concentration, $\mathrm{C}_{\mathrm{f}}$ is final cesium concentration, $\mathrm{V}$ is the volume of solution, $\mathrm{m}$ is the mass of resin, and $\mathrm{F}$ is the F-factor of the resin. Note that $\mathrm{V} /(\mathrm{mF})$ is the phase ratio given in the Table. Note further that the initial cesium concentration has been corrected for the dilution that ensues from the water in the resin.

The data for the as-received Tank $2 \mathrm{~F}$ simulant solution compare reasonably well with those obtained from previous testing using the same simulant. ${ }^{7}$ This instills confidence in the eluant testing data. It also reaffirms that the quality of the preconditioned sRF resin used for this study is good as far as degradation is concerned.

The data for the spiked Tank 2F simulant solution serve as a benchmark for this non-acid elution study. Since the sRF resin is designed to have high cesium sorption affinity (or $\mathrm{K}_{\mathrm{d}}$ 's) from highly alkaline solutions, the $\mathrm{K}_{\mathrm{d}}$ value of $212 \mathrm{~L} / \mathrm{kg}$ for the spiked Tank $2 \mathrm{~F}$ simulant solution is roughly the demarcation or cutoff value for this study. A $K_{d}$ value $<212 \mathrm{~L} / \mathrm{kg}$ from the eluant cesium sorption equilibrium screening test means the eluant has a relatively high/moderate cesium elution potential while a $\mathrm{K}_{\mathrm{d}}$ value $>212 \mathrm{~L} / \mathrm{kg}$ implies an eluant with a low cesium elution potential. 
A comparison of the 192-hour data for 2 $\mathrm{M}$ ammonium carbonate solution with the corresponding data for the spiked Tank $2 \mathrm{~F}$ simulant solution (i.e., the two rows in bold) indicates $\sim 2 \mathrm{M}$ ammonium carbonate solution holds promise for cesium elution $\left(\mathrm{K}_{\mathrm{d}}\right.$ of 10.9 versus $212 \mathrm{~L} / \mathrm{kg}$ ). The percent RSD for the $\mathrm{K}_{\mathrm{d}}$ 's of all the replicates are $<19 \%-\mathrm{An}$ indication of good replications.

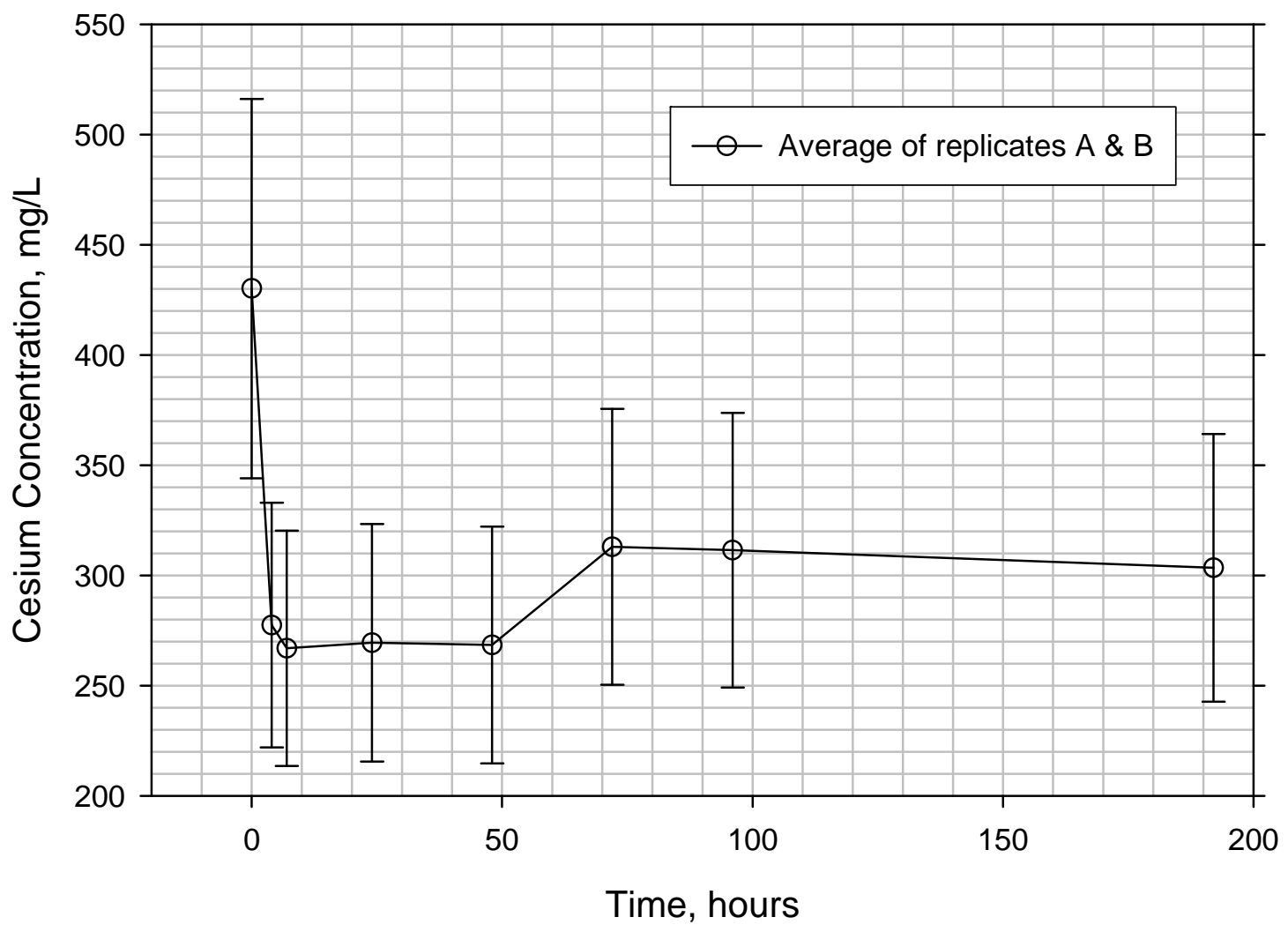

Figure 1. Cesium Sorption Kinetics for $\sim 2 \mathrm{M}$ Ammonium Carbonate Solution and sRF Resin. 
Table 2. Cesium Sorption Kinetics for $\sim 2 \mathrm{M}$ Ammonium Carbonate and sRF Resin at $25{ }^{\circ} \mathrm{C}$.

\begin{tabular}{|c|c|c|c|c|c|c|c|c|c|c|}
\hline & $\begin{array}{c}\text { Replicate } \\
\text { A }\end{array}$ & $\begin{array}{c}\text { Replicate } \\
\text { B }\end{array}$ & $\begin{array}{c}\text { Replicate } \\
\text { A }\end{array}$ & $\begin{array}{c}\text { Replicate } \\
\text { B }\end{array}$ & $\begin{array}{c}\text { Replicate } \\
\text { A }\end{array}$ & $\begin{array}{c}\text { Replicate } \\
\text { B }\end{array}$ & $\begin{array}{c}\text { Replicate } \\
\text { A }\end{array}$ & $\begin{array}{c}\text { Replicate } \\
\text { B }\end{array}$ & Average & $\begin{array}{c}\text { Percent } \\
\text { RSD }\end{array}$ \\
\hline Time & $\begin{array}{c}\text { Cesium } \\
\text { Conc. }\end{array}$ & $\begin{array}{c}\text { Cesium } \\
\text { Conc. }\end{array}$ & $\begin{array}{l}\text { Phase } \\
\text { Ratio }\end{array}$ & $\begin{array}{l}\text { Phase } \\
\text { Ratio }\end{array}$ & $\begin{array}{l}\text { Cesium } \\
\text { Sorbed }\end{array}$ & $\begin{array}{l}\text { Cesium } \\
\text { Sorbed }\end{array}$ & $\mathbf{K}_{\mathbf{d}}$ & $\mathbf{K}_{\mathbf{d}}$ & $\mathbf{K}_{\mathbf{d}}$ & \\
\hline Hours & $\mathrm{mg} / \mathrm{L}$ & $\mathrm{mg} / \mathrm{L}$ & $\mathrm{L} / \mathrm{kg}$ & $\mathrm{L} / \mathrm{kg}$ & $\mathrm{mg} / \mathrm{kg}$ & $\mathrm{mg} / \mathrm{kg}$ & $\mathrm{L} / \mathrm{kg}$ & $\mathrm{L} / \mathrm{kg}$ & $\mathrm{L} / \mathrm{kg}$ & $\%$ \\
\hline \multicolumn{11}{|c|}{ 2 M Ammonium Carbonate Solution } \\
\hline 0 & 426 & 435 & $\mathrm{n} / \mathrm{a}$ & $\mathrm{n} / \mathrm{a}$ & $\mathrm{n} / \mathrm{a}$ & $\mathrm{n} / \mathrm{a}$ & $\mathrm{n} / \mathrm{a}$ & $\mathrm{n} / \mathrm{a}$ & $\mathrm{n} / \mathrm{a}$ & $\mathrm{n} / \mathrm{a}$ \\
\hline 4 & 271 & 284 & 26.1 & 26.1 & 4,030 & 3,933 & 14.9 & 13.8 & 14.4 & 5.04 \\
\hline 7 & 259 & 275 & 26.1 & 26.4 & 4,350 & 4,212 & 16.8 & 15.3 & 16.1 & 6.51 \\
\hline 24 & 268 & 271 & 26.1 & 26.2 & 4,115 & 4,282 & 15.4 & 15.8 & 15.6 & 2.01 \\
\hline 48 & 266 & 271 & 26.2 & 26.1 & 4,172 & 4,272 & 15.7 & 15.8 & 15.7 & 0.36 \\
\hline 72 & 308 & 318 & 26.2 & 26.1 & 3,075 & 3,044 & 10.0 & 9.6 & 9.78 & 2.97 \\
\hline 96 & 320 & 303 & 26.2 & 26.1 & 2,761 & 3432 & 8.6 & 11.3 & 10.0 & 19.1 \\
\hline 192 & 309 & 298 & 26.2 & 26.1 & 3,058 & 3,571 & 9.9 & 12.0 & 10.9 & 13.5 \\
\hline \multicolumn{11}{|c|}{ Spiked Tank 2F Simulant Solution } \\
\hline 0 & 424 & 425 & $\mathrm{n} / \mathrm{a}$ & $\mathrm{n} / \mathrm{a}$ & $\mathrm{n} / \mathrm{a}$ & $\mathrm{n} / \mathrm{a}$ & $\mathrm{n} / \mathrm{a}$ & $\mathrm{n} / \mathrm{a}$ & $\mathrm{n} / \mathrm{a}$ & $\mathrm{n} / \mathrm{a}$ \\
\hline 192 & 43.5 & 49.9 & 26.1 & 26.1 & 9,914 & 9,786 & 228 & 196 & 212 & 10.6 \\
\hline \multicolumn{11}{|c|}{ As-Received Tank 2F Simulant Solution } \\
\hline 0 & 2.24 & 2.24 & $\mathrm{n} / \mathrm{a}$ & $\mathrm{n} / \mathrm{a}$ & $\mathrm{n} / \mathrm{a}$ & $\mathrm{n} / \mathrm{a}$ & $\mathrm{n} / \mathrm{a}$ & $\mathrm{n} / \mathrm{a}$ & $\mathrm{n} / \mathrm{a}$ & $\mathrm{n} / \mathrm{a}$ \\
\hline 192 & 0.0485 & 0.056 & 26.1 & 26.2 & 57.3 & 57.1 & 1,182 & 1,019 & 1,100 & 10.4 \\
\hline
\end{tabular}

All the sorption calculations are based on Na-form resin $\mathrm{n} / \mathrm{a}=$ not applicable 


\subsection{SORPTION EQUILIBRIUM SCREENING TESTS}

Table 3 shows the cesium sorption data from the equilibrium screening tests along with the kinetics data for the $\sim 2 \mathrm{M}$ ammonium carbonate solution (48-hour equilibration time) and the spiked Tank 2F simulant solution (192-hour equilibration time) for comparison. Recall, the 192hour spiked Tank 2F simulant solution sorption data is currently the benchmark until a 48-hour sorption equilibration data become available. A 48-hour sorption equilibration time test for the spiked Tank 2F simulant solution is slated for the next phase of testing. The cesium sorption equilibrium time for sRF/simulant solutions is typically 48 hours. ${ }^{22}$ Hence, the 48-hour sorption data are not expected to be significantly different from the 192-hour sorption data.

The following general comments on Table 3 are in order prior to discussing its specifics.

- The sorption equilibrium screening tests were done in three sets or batches.

- Some tests involved two compounds, specifically the hydroxides of the cation of the eluant. They were attempts to see if the hydroxides enhanced the elution potential of the eluants.

- Values in italics have either significantly different replicate values or significantly lower/higher initial cesium concentrations than the target values (459 or $458 \mathrm{mg} / \mathrm{L}$ ).

It is not clear why the initial cesium concentration of $\sim 1.8 \mathrm{M}$ ammonium bicarbonate $/ 1 \mathrm{M}$ ammonium hydroxide solution (Equilibrium Test - Set 3) was very low even though the $K_{d}$ seems fairly credible when compared with the $\mathrm{K}_{\mathrm{d}}$ for $\sim 1.8 \mathrm{M}$ ammonium bicarbonate solution (Equilibrium Test - Set 2). Same comment also applies to 3M rubidium carbonate solution (Equilibrium Test - Set 1) which is on the high side.

The relatively low initial cesium concentration of $1 \mathrm{M}$ tetrabutylphosphonium hydroxide (Equilibrium Test - Set 1); and $1 \mathrm{M}, 0.1 \mathrm{M}$, and $0.03 \mathrm{M}$ tetramethylammonium hydroxide (Equilibrium Test - Set 1, 2, and 2) solutions may be due to the fact that they may be above their respective critical micelle concentrations (CMC). Above the CMC, micelle or colloid formation prevails which may have skewed the cesium concentration to the low side. It is quite possible colloidal particles (micelles) with cesium attached or embedded in them may have deposited in the syringe filter membrane and on the walls of the vials, etc.

Even though the CMC of the above compounds are unknown, CMC values typically range in the fraction of a millimolar to several millimolar. Along the same lines, micelle formation may have obscured evaluation of their elution potential even though it will be shown later (Table 8) that generally high pH's ( $>11$ ) seem not to favor cesium elution from sRF i.e., result in relatively high $K_{d}$ 's. The fairly high initial cesium concentrations of the other surfactants used (i.e., all the remaining organics tested) lend some support to the above claim because their concentrations are generally low.

With the exception of a few eluants, the percent RSD of the $\mathrm{K}_{\mathrm{d}}$ 's are reasonably low. However, comparison of the 48-hour kinetics and 48-hour equilibrium $K_{d}$ values for $\sim 2 \mathrm{M}$ ammonium carbonate solution shows some disparity ( 15.7 versus $2.62 \mathrm{~L} / \mathrm{kg}$ ). It may be due to difference in initial concentration which may be from difference in their preparation. Recall, it was mentioned in subsection 2.1.4 that the concentration of the ammonium carbonate solution is approximate 
because of lack of complete dissolution during preparation. During filtration of the first ammonium carbonate solution (i.e., for the 48-hour kinetics test), the undissolved solids were captured to roughly determine their amount. It led to the rinsing of the volumetric flask with deionized water to get all the solids out. The rinsing may have resulted in more dilution for the solution used for the 48-hour kinetics test.

Because some of the initial cesium concentrations of the eluant solutions were significantly lower (or higher in the case of rubidium carbonate) than their respective target initial cesium concentrations, what-if scenario $K_{d}$ calculations were done for those eluants to make sure the $K_{d}$ comparisons are made on an equal-concentration basis. This ensures no eluant whose elution potential is high is missed.

The what-if scenarios data are given in Tables 4 to 7 . Only the ratio of the initial cesium concentration to the target initial cesium concentration is given for the eluants whose initial cesium concentrations were not significantly different from the target initial cesium concentrations. For $\sim 1.8 \mathrm{M}$ ammonium bicarbonate/1 M ammonium hydroxide solution (Table 6, Equilibrium Test - Set 3), a what-if scenario calculation was not done. The initial cesium concentration was extremely low $(1.11$ and $1.10 \mathrm{mg} / \mathrm{L}$ for two replicates versus a target of 459 $\mathrm{mg} / \mathrm{L}$ ) that the results will not be practical.

As an example, 3M rubidium carbonate solution (Table 4, Equilibrium Test - Set 1) has an initial cesium concentration that is about 1.3 times higher than the target initial cesium concentration. However, the what-if scenario $K_{d}$ values indicate the $K_{d}$ 's would have been still fairly low (a range of 2 to $7 \mathrm{~L} / \mathrm{kg}$ ) had the initial cesium concentration been close to the target. This approach therefore erases any doubts as to the high elution potential of 3M rubidium carbonate solution.

Table 8 gives a ranking of the eluant solutions tested along with their pre-test or as-prepared $\mathrm{pH}$ and elution potential category. The rankings are based solely on the average $K_{d}$ values without consideration of the downstream impacts. The ranks of the eluants are given in decreasing order of cesium elution potential (i.e., increasing $K_{d}$ values). Three $K_{d}$ values (average, low, and high) are given for the eluants whose replicate values are significantly different even though the ranks are based on the average values. Apparently, the low and high $K_{d}$ values had minimal impact on the ranking. Note that two values for a $\mathrm{pH}$ imply it was measured twice for that particular eluant over a course of several days to weeks as a confirmation.

The elution potential categories are based directly on the average $K_{d}$ values and indirectly on the initial cesium concentration. The initial concentration factors in from the what-if scenarios due to some of the eluants having initial cesium concentrations somewhat significantly different from the target as mentioned earlier. The range of the what-if scenarios $K_{d}$ values are given in the “cesium elution potential” column (i.e., last column), if applicable.

In Table 8, an eluant is deemed to have a high cesium elution potential if its $\mathrm{K}_{\mathrm{d}}$ value is $<\sim 100$ $\mathrm{L} / \mathrm{kg}$. A $\mathrm{K}_{\mathrm{d}}$ value of between $\sim 100$ to $\sim 200 \mathrm{~L} / \mathrm{kg}$ puts the eluant in the moderate cesium elution potential category. A low cesium elution potential designation is given to an eluant with a $\mathrm{K}_{\mathrm{d}}$ value $>\sim 200 \mathrm{~L} / \mathrm{kg}$. Note that the above categories are not hard-and-fast. They were based on 
using the $\mathrm{K}_{\mathrm{d}}$ value of the spiked Tank $2 \mathrm{~F}$ Simulant (i.e., $212 \mathrm{~L} / \mathrm{kg}$ ) as a benchmark or the preliminary cutoff $\mathrm{K}_{\mathrm{d}}$ value as was previously mentioned in subsections 2.2.1 and 3.2.

The ammonium compounds as a group clearly stand out as the most promising eluants with rubidium carbonate, calcium chloride, magnesium chloride hexahydrate solutions among the top ten overall. The organic and sodium compounds are generally at the bottom half of the ranking. As alluded to earlier, ammonium compounds, especially ammonium carbonate has been used successfully in the past to elute cesium from other organic and inorganic ion exchange resins/materials. ${ }^{14-21}$

On the whole, high $\mathrm{pH}$ (i.e., $\mathrm{pH}>12$ ) eluant solutions had mediocre performance except potassium compounds. Put differently, eluants with $\mathrm{pH}$ 's of $\leq 11$ had promising performance except some of the organics, $0.75 \mathrm{M}$ sodium bicarbonate, and $0.75 \mathrm{M}$ sodium bicarbonate/0.5M sodium hydroxide solutions. Supporting evidence is the fact that most of the hydroxides (except potassium hydroxide) are at the bottom of the ranking because they are high $\mathrm{pH}$ solutions. The sRF resin was designed to have high affinity for cesium (and unavoidably or inadvertently for potassium and possibly rubidium because they are also in group I of the periodic table) in high pH (i.e., > 11) media or solutions. ${ }^{22}$ The data in Table 8 appear to suggest for the other cations to be effective (or to suppress cesium sorption) the $\mathrm{pH}$ of their eluant solutions has to be between $\sim 5$ and $\sim 10$ as shown by the top nine performers and certainly by the ammonium compounds. It is worth emphasizing that the $\mathrm{pH}$ measurements were performed with $\mathrm{pH}$ indicator strips (colorpHast pH test strips - EMD Chemicals, Gibbstown, New Jersey).

For $3 \mathrm{M}$ potassium carbonate, $3 \mathrm{M}$ potassium bicarbonate, and $0.03 \mathrm{M}$ tetramethylammonium chloride solutions; addition of their respective hydroxides tends to enhance the elution potential. For the potassium compounds, this is consistent with the statement made earlier that the sRF resin works best at high $\mathrm{pH}$ for potassium, cesium, and possibly rubidium despite the fact that the percent RSD of the $K_{d}$ value for the $3 \mathrm{M}$ potassium carbonate/0.5 M potassium hydroxide solution is fairly high.

For $2 \mathrm{M}$ ammonium acetate, $1.8 \mathrm{M}$ ammonium bicarbonate, $\sim 2 \mathrm{M}$ ammonium carbonate, $2 \mathrm{M}$ lithium chloride, and 1.8 M lithium sulfate solutions; addition of their respective hydroxides did not enhance the elution potential. Again, the percent RSD of the $K_{d}$ value for the $\sim 2 \mathrm{M}$ ammonium carbonate/1 M ammonium hydroxide solution is fairly high. Also, the $\mathrm{K}_{\mathrm{d}}$ value for 2 $\mathrm{M}$ ammonium acetate and $2 \mathrm{M}$ ammonium acetate/1.5 $\mathrm{M}$ ammonium hydroxide solutions are close. As mentioned earlier, ammonium hydroxide enhanced the elution potential of ammonium carbonate for other resins. It seems the hydroxide enhancement is resin-specific.

The overall data suggest the following speculations are in order. For $2 \mathrm{M}$ ammonium acetate/1.5 $\mathrm{M}$ ammonium hydroxide solution, reducing the ammonium hydroxide concentration to bring the $\mathrm{pH}$ of the solution to about 9 may boost the elution potential. Same comment holds for $2 \mathrm{M}$ lithium chloride/ 1 M lithium hydroxide and 1.8 M lithium sulfate/ 0.5 M lithium hydroxide; and to a lesser degree (because their elution ability is generally low) for $0.75 \mathrm{M}$ sodium bicarbonate/0.5 M sodium hydroxide and $0.03 \mathrm{M}$ tetramethylammonium chloride/0.03 $\mathrm{M}$ tetramethylammonium hydroxide. Similarly, boosting the $\mathrm{pH}$ of $2 \mathrm{M}$ calcium chloride and $3 \mathrm{M}$ magnesium chloride hexahydrate to about 9 may enhance their elution potential. 
SRNL-STI-2010-00563, REV. 0

The foregoing provides strong incentive for studies on optimization of eluant concentration and $\mathrm{pH}$ among others after the completion of this ongoing study. 
Table 3. Data for Cesium Sorption Equilibrium Screening Tests at $25{ }^{\circ} \mathrm{C}-$ Sets 1,2 \& 3.

\begin{tabular}{|c|c|c|c|c|c|c|c|c|c|c|c|c|}
\hline & \multicolumn{2}{|c|}{ Replicates } & \multicolumn{2}{|c|}{ Replicates } & \multicolumn{2}{|c|}{ Replicates } & \multicolumn{2}{|c|}{ Replicates } & \multicolumn{2}{|c|}{ Replicates } & \multirow[b]{2}{*}{ Average } & \multirow{2}{*}{$\begin{array}{l}\text { Percent } \\
\text { RSD }\end{array}$} \\
\hline & A & B & $\mathbf{A}$ & B & A & $\mathbf{B}$ & $\overline{\mathbf{A}}$ & B & $\mathbf{A}$ & B & & \\
\hline Eluant Solution & $\begin{array}{c}\text { Initial } \\
\text { Cesium } \\
\text { Conc. }\end{array}$ & $\begin{array}{c}\text { Initial } \\
\text { Cesium } \\
\text { Conc. }\end{array}$ & $\begin{array}{c}\text { Final } \\
\text { Cesium } \\
\text { Conc. }\end{array}$ & $\begin{array}{c}\text { Final } \\
\text { Cesium } \\
\text { Conc. }\end{array}$ & $\begin{array}{l}\text { Phase } \\
\text { Ratio }\end{array}$ & $\begin{array}{l}\text { Phase } \\
\text { Ratio }\end{array}$ & $\begin{array}{l}\text { Cesium } \\
\text { Sorbed }\end{array}$ & $\begin{array}{l}\text { Cesium } \\
\text { Sorbed }\end{array}$ & $\mathbf{K}_{\mathbf{d}}$ & $\mathbf{K}_{\mathbf{d}}$ & $\mathbf{K}_{\mathbf{d}}$ & \\
\hline & $\mathrm{mg} / \mathrm{L}$ & $\mathrm{mg} / \mathrm{L}$ & $\mathrm{mg} / \mathrm{L}$ & $\mathrm{mg} / \mathrm{L}$ & $\mathrm{L} / \mathrm{kg}$ & $\mathrm{L} / \mathrm{kg}$ & $\mathrm{mg} / \mathrm{kg}$ & $\mathrm{mg} / \mathrm{kg}$ & $\mathrm{L} / \mathrm{kg}$ & $\mathrm{L} / \mathrm{kg}$ & $\mathrm{L} / \mathrm{kg}$ & $\%$ \\
\hline \multicolumn{13}{|l|}{ Equilibrium Test - Set 1} \\
\hline 3 M Potassium Carbonate & 486 & 478 & 169 & 137 & 26.2 & 26.2 & 8,306 & 8,918 & 49.1 & 65.1 & 57.1 & 19.7 \\
\hline 3 M Potassium Hydroxide & 476 & 469 & 117 & 120 & 26.2 & 26.1 & 9,412 & 9,095 & 80.4 & 75.8 & 78.1 & 4.21 \\
\hline 3 M Rubidium Carbonate & 593 & 611 & 506 & 491 & 26.1 & 26.1 & 2,275 & 3,121 & 4.50 & 6.36 & 5.43 & 24.2 \\
\hline 1.5 M Sodium Carbonate & 477 & 469 & 17.1 & 20.7 & 26.1 & 26.1 & 12,006 & 11,689 & 702 & 565 & 633 & 15.3 \\
\hline 3 M Sodium Hydroxide & 449 & 463 & 5.82 & 6.35 & 26.2 & 26.2 & 11,600 & 11,955 & 1,993 & 1,883 & 1,938 & 4.03 \\
\hline 1 M Tetrabutylphosphonium Hydroxide & 378 & 374 & 11.5 & 13.8 & 26.2 & 26.1 & 9,581 & 9,416 & 833 & 682 & 758 & 14.1 \\
\hline $1 \mathrm{M}$ Tetramethylammonium Hydroxide & 369 & 376 & 28.7 & 22.1 & 26.2 & 26.1 & 8,907 & 9,249 & 310 & 418 & 364 & 21.0 \\
\hline \multicolumn{13}{|l|}{ Equilibrium Test - Set 2} \\
\hline 2 M Ammonium Acetate & 431 & 457 & 336 & 352 & 26.2 & 26.2 & 2,487 & 2,738 & 7.40 & 7.78 & 7.59 & 3.53 \\
\hline 1.8 M Ammonium Bicarbonate & 435 & 433 & 355 & 365 & 26.2 & 26.2 & 2,087 & 1,777 & 5.88 & 4.87 & 5.37 & 13.3 \\
\hline 2 M Ammonium Carbonate & 438 & 434 & 395 & 398 & 26.2 & 26.2 & 1,136 & 938 & 2.88 & 2.36 & 2.62 & 14.1 \\
\hline $\begin{array}{l}\sim 2 \mathrm{M} \text { Ammonium Carbonate/1 M } \\
\text { Ammonium Hydroxide }\end{array}$ & 386 & 394 & 344 & 335 & 26.2 & 26.2 & 1,102 & 1,553 & 3.20 & 4.64 & 3.92 & 25.9 \\
\hline 2 M Calcium Chloride & 439 & 429 & 307 & 233 & 26.2 & 26.2 & 3,462 & 5,136 & 11.3 & 22.0 & 16.7 & 45.7 \\
\hline $\begin{array}{l}0.03 \text { M Hexadecyltrimethylammonium } \\
\text { Chloride }\end{array}$ & 439 & 447 & 46.1 & 51.3 & 26.2 & 26.2 & 10,292 & 10,346 & 223 & 201 & 212 & 7.18 \\
\hline 2 M Lithium Chloride & 433 & 422 & 141 & 90.5 & 26.2 & 26.2 & 7,650 & 8,668 & 54.3 & 95.8 & 75.0 & 39.1 \\
\hline $\begin{array}{l}2.7 \text { M Lithium Hydroxide } \\
\end{array}$ & 422 & 415 & 2.80 & 2.18 & 26.2 & 26.2 & 10,966 & 10,816 & 3,916 & 4,962 & 4,439 & 16.7 \\
\hline 1.8 M Lithium Sulfate & 435 & 423 & 134 & 129 & 26.2 & 26.2 & 7,868 & 7,685 & 58.7 & 59.6 & 59.1 & 1.02 \\
\hline 3 M Magnesium Chloride Hexahydrate & 389 & 400 & 168 & 180 & 26.2 & 26.2 & 5,784 & 5,756 & 34.4 & 32.0 & 33.2 & 5.22 \\
\hline 1.8 M Magnesium Sulfate & 437 & 432 & 109 & 109 & 26.2 & 26.2 & 8,570 & 8,452 & 78.6 & 77.5 & 78.1 & 0.98 \\
\hline 1.7 M Potassium Bicarbonate & 453 & 445 & 38.6 & 39.7 & 26.2 & 26.2 & 10,822 & 10,599 & 280 & 267 & 274 & 3.46 \\
\hline 0.75 M Sodium Bicarbonate & 418 & 462 & 29.7 & 30.3 & 26.2 & 26.2 & 10,164 & 11,289 & 342 & 373 & 357 & 6.01 \\
\hline $\begin{array}{l}0.03 \mathrm{M} \text { Tetramethylammonium } \\
\text { Hydroxide }\end{array}$ & 355 & 371 & 1.59 & 2.23 & 26.2 & 26.2 & 9,242 & 9,658 & 5,812 & 4,331 & 5,072 & 20.7 \\
\hline $\begin{array}{l}0.1 \mathrm{M} \text { Tetramethylammonium } \\
\text { Hydroxide }\end{array}$ & 320 & 323 & 6.81 & 6.09 & 26.2 & 26.2 & 8,193 & 8,283 & 1,203 & 1,360 & 1,282 & 8.66 \\
\hline \multicolumn{13}{|l|}{ Equilibrium Test - Set 3} \\
\hline $\begin{array}{l}2 \mathrm{M} \text { Ammonium Acetate } / 1.5 \mathrm{M} \\
\text { Ammonium Hydroxide }\end{array}$ & 415 & 410 & 310 & 304 & 26.2 & 26.2 & 2,735 & 2,772 & 8.82 & 9.12 & 8.97 & 2.32 \\
\hline $\begin{array}{l}\text { 1.8 M Ammonium Bicarbonate/1M } \\
\text { Ammonium Hydroxide }\end{array}$ & 1.11 & 1.10 & 0.778 & 0.739 & 26.2 & 26.2 & 8.68 & 9.46 & 11.16 & 12.81 & 12.0 & 9.75 \\
\hline
\end{tabular}


SRNL-STI-2010-00563, REV. 0

\begin{tabular}{|c|c|c|c|c|c|c|c|c|c|c|c|c|}
\hline & \multicolumn{2}{|c|}{ Replicates } & \multicolumn{2}{|c|}{ Replicates } & \multicolumn{2}{|c|}{ Replicates } & \multicolumn{2}{|c|}{ Replicates } & \multicolumn{2}{|c|}{ Replicates } & \multirow[b]{2}{*}{ Average } & \multirow{2}{*}{$\begin{array}{l}\text { Percent } \\
\text { RSD }\end{array}$} \\
\hline & A & B & A & B & A & B & A & B & A & B & & \\
\hline Eluant Solution & $\begin{array}{c}\text { Initial } \\
\text { Cesium } \\
\text { Conc. }\end{array}$ & $\begin{array}{c}\text { Initial } \\
\text { Cesium } \\
\text { Conc. }\end{array}$ & $\begin{array}{l}\text { Final } \\
\text { Cesium } \\
\text { Conc. }\end{array}$ & $\begin{array}{l}\text { Final } \\
\text { Cesium } \\
\text { Conc. }\end{array}$ & $\begin{array}{l}\text { Phase } \\
\text { Ratio }\end{array}$ & $\begin{array}{l}\text { Phase } \\
\text { Ratio }\end{array}$ & $\begin{array}{l}\text { Cesium } \\
\text { Sorbed }\end{array}$ & $\begin{array}{l}\text { Cesium } \\
\text { Sorbed }\end{array}$ & $\mathbf{K}_{\mathbf{d}}$ & $\mathbf{K}_{\mathbf{d}}$ & $\mathbf{K}_{\mathbf{d}}$ & \\
\hline & $\mathrm{mg} / \mathrm{L}$ & $\mathrm{mg} / \mathrm{L}$ & $\mathrm{mg} / \mathrm{L}$ & $\mathrm{mg} / \mathrm{L}$ & $\mathrm{L} / \mathrm{kg}$ & $\mathrm{L} / \mathrm{kg}$ & $\mathrm{mg} / \mathrm{kg}$ & $\mathrm{mg} / \mathrm{kg}$ & $\mathrm{L} / \mathrm{kg}$ & $\mathrm{L} / \mathrm{kg}$ & $\mathrm{L} / \mathrm{kg}$ & $\%$ \\
\hline \multicolumn{13}{|l|}{ Equilibrium Test - Set 3 Cont'd } \\
\hline $\begin{array}{l}0.05 \text { M Hexadecyltrimethylammonium } \\
\text { Chloride }\end{array}$ & 419 & 456 & 58.9 & 45.4 & 26.2 & 26.2 & 9,429 & 10,739 & 160 & 237 & 198 & 27.3 \\
\hline $\begin{array}{l}2 \text { M Lithium Chloride/ 1 M Lithium } \\
\text { Hydroxide }\end{array}$ & 424 & 426 & 8.02 & 16.7 & 26.1 & 26.12 & 10,847 & 10,716 & 1,352 & 642 & 997 & 50.4 \\
\hline $\begin{array}{l}\text { 1.8 M Lithium Sulfate/ } 0.5 \text { M Lithium } \\
\text { Hydroxide }\end{array}$ & 467 & 435 & 23.5 & 21.1 & 26.2 & 26.2 & 11,597 & 10,823 & 493 & 513 & 503 & 2.73 \\
\hline $\begin{array}{l}\sim 1.7 \text { M Potassium Bicarbonate/ } 0.5 \mathrm{M} \\
\text { Potassium Hydroxide }\end{array}$ & 405 & 409 & 116 & 78.6 & 26.2 & 26.2 & 7,571 & 8,647 & 65.3 & 110 & 87.6 & 36.1 \\
\hline $\begin{array}{l}3 \mathrm{M} \text { Potassium Carbonate } / 0.5 \mathrm{M} \\
\text { Potassium Hydroxide }\end{array}$ & 444 & 447 & 135 & 179 & 26.2 & 26.2 & 8,087 & 7,010 & 59.9 & 39.2 & 49.5 & 29.6 \\
\hline $\begin{array}{l}0.75 \text { M Sodium Bicarbonate } / 0.5 \mathrm{M} \\
\text { Sodium Hydroxide }\end{array}$ & 462 & 454 & 30.9 & 28.0 & 26.2 & 26.2 & 11,292 & 11,143 & 365 & 398 & 382 & 6.02 \\
\hline $\begin{array}{l}\text { 1.5 M Sodium Carbonate/ } 0.5 \mathrm{M} \\
\text { Sodium Hydroxide }\end{array}$ & 443 & 434 & 11.10 & 8.97 & 26.2 & 26.2 & 11,298 & 11,112 & 1,018 & 1,239 & 1,128 & 13.9 \\
\hline $\begin{array}{l}0.03 \text { M Tetrabutylphosphonium } \\
\text { Hydroxide }\end{array}$ & 442 & 446 & 3.36 & 3.97 & 26.2 & 26.2 & 11,475 & 11,567 & 3,415 & 2,914 & 3,164 & 11.2 \\
\hline $\begin{array}{l}0.05 \mathrm{M} \text { Tetrabutylphosphonium } \\
\text { Hydroxide }\end{array}$ & 418 & 415 & 2.86 & 2.66 & 26.2 & 26.2 & 10,881 & 10,772 & 3,804 & 4,050 & 3,927 & 4.42 \\
\hline $\begin{array}{l}0.03 \mathrm{M} \text { Tetramethylammonium } \\
\text { Chloride }\end{array}$ & 414 & 413 & 13.1 & 35.2 & 26.2 & 26.2 & 10,475 & 9,874 & 800 & 280 & 540 & 68.0 \\
\hline $\begin{array}{l}0.03 \mathrm{M} \text { Tetramethylammonium } \\
\text { Chloride/0.03 M } \\
\text { Tetramethylammonium Hydroxide }\end{array}$ & 429 & 445 & 27.0 & 26.5 & 26.2 & 26.2 & 10,518 & 10,940 & 390 & 413 & 401 & 4.10 \\
\hline $\begin{array}{l}0.03 \mathrm{M} \text { Tetramethylphosphonium } \\
\text { Bromide }\end{array}$ & 426 & 415 & 23.1 & 21.8 & 26.2 & 26.2 & 10,557 & 10,274 & 457 & 471 & 464 & 2.18 \\
\hline \multicolumn{13}{|l|}{ Kinetics Test } \\
\hline 2 M Ammonium Carbonate & 426 & 435 & 266 & 271 & 26.2 & 26.1 & 4,172 & 4,272 & 15.7 & 15.8 & 15.7 & 0.36 \\
\hline Spiked Tank 2F Simulant $^{\mathrm{a}}$ & 424 & 425 & 43.5 & 49.9 & 26.1 & 26.1 & 9,914 & 9,786 & 228 & 196 & $212^{b}$ & 10.6 \\
\hline
\end{tabular}

Equilibration time $=48$ hours except Spiked Tank $2 \mathrm{~F}$ Simulant.

${ }^{\mathrm{a}}$ Equilibration time $=192$ hours

${ }^{\mathrm{b}}$ 48-hour prediction based on ammonium carbonate kinetic behavior $=305 \mathrm{~L} / \mathrm{kg}$

All the sorption calculations are based on Na-form resin

Values in italics have either significantly different replicate values or significantly lower/higher initial cesium concentrations than the target values (459 or $458 \mathrm{mg} / \mathrm{L}$ ).

The molar concentration of the cations of the carbonate compounds is twice the molar concentration of the respective carbonate compound given above. 
Table 4. What-If Scenarios for Initial Cesium Concentration (Sorption Equilibrium Screening Test Set 1 ).

\begin{tabular}{|c|c|c|c|c|c|c|}
\hline \multicolumn{7}{|c|}{3 M Rubidium Carbonate } \\
\hline \multicolumn{5}{|c|}{ Initial cesium concentration/Target initial cesium concentration Ratio $=1.313$} & \multicolumn{2}{|c|}{$\mathrm{T}_{\mathrm{i}}=458$} \\
\hline \multicolumn{2}{|c|}{ Actual Sorption Data } & \multicolumn{5}{|c|}{ What-If Scenarios } \\
\hline $\mathrm{C}_{\mathrm{i}}=$ & 602 & If $\mathrm{C}_{\mathrm{i}}=$ & 458 & 458 & 458 & 458 \\
\hline $\mathrm{dC}=$ & 103 & and $\mathrm{dC}=$ & 30 & 50 & 80 & 95 \\
\hline $\mathrm{C}_{\mathrm{f}}=$ & 499 & then $\mathrm{C}_{\mathrm{f}}=$ & 428 & 408 & 378 & 363 \\
\hline $\mathrm{S}=$ & 2,698 & $\mathrm{~S}=$ & 782 & 1,304 & 2,086 & 2,478 \\
\hline $\mathrm{K}_{\mathrm{d}}=$ & 5 & $\mathrm{~K}_{\mathrm{d}}=$ & 2 & 3 & 6 & 7 \\
\hline \multicolumn{7}{|c|}{1 M Tetrabutylphosphonium Hydroxide } \\
\hline \multirow{2}{*}{\multicolumn{5}{|c|}{ Initial cesium concentration/Target initial cesium concentration Ratio $=0.820$}} & \multicolumn{2}{|c|}{$\mathrm{T}_{\mathrm{i}}=459$} \\
\hline & Actual Sorption Data & \multicolumn{5}{|c|}{ What-If Scenarios } \\
\hline $\mathrm{C}_{\mathrm{i}}=$ & 376 & If $C_{i}=$ & 459 & 459 & 459 & 459 \\
\hline $\mathrm{dC}=$ & 363 & and $\mathrm{dC}=$ & 383 & 403 & 430 & 363 \\
\hline $\mathrm{C}_{\mathrm{f}}=$ & 12.7 & then $\mathrm{C}_{\mathrm{f}}=$ & 76 & 56 & 29 & 96 \\
\hline $\mathrm{S}=$ & 9,499 & $\mathrm{~S}=$ & 10,012 & 10,534 & 11,240 & 9,489 \\
\hline $\mathrm{K}_{\mathrm{d}}=$ & 758 & $K_{d}=$ & 133 & 190 & 394 & 99 \\
\hline \multicolumn{7}{|c|}{1 M Tetramethylammonium Hydroxide } \\
\hline \multicolumn{5}{|c|}{ Initial cesium concentration/Target initial c } & \multicolumn{2}{|c|}{$\mathrm{T}_{\mathrm{i}}=459$} \\
\hline \multicolumn{2}{|c|}{ Actual Sorption Data } & \multicolumn{5}{|c|}{ What-If Scenarios } \\
\hline $\mathrm{C}_{\mathrm{i}}=$ & 372 & If $C_{i}=$ & 459 & 459 & 459 & 459 \\
\hline $\mathrm{dC}=$ & 347 & and $\mathrm{dC}=$ & 367 & 387 & 415 & 347 \\
\hline $\mathrm{C}_{\mathrm{f}}=$ & 25.4 & then $C_{f}=$ & 92 & 72 & 44 & 112 \\
\hline $\mathrm{S}=$ & 9,078 & $S=$ & 9,603 & 10,126 & 10,858 & 9,079 \\
\hline $\mathrm{K}_{\mathrm{d}}=$ & 364 & $K_{d}=$ & 105 & 141 & 249 & 81 \\
\hline \multicolumn{7}{|c|}{3 M Potassium Carbonate } \\
\hline \multicolumn{5}{|c|}{ Initial cesium concentration/Target initial cesium concentration Ratio $=1.051$} & \multicolumn{2}{|c|}{$\mathrm{T}_{\mathrm{i}}=459$} \\
\hline \multicolumn{7}{|c|}{3 M Potassium Hydroxide } \\
\hline \multicolumn{5}{|c|}{ Initial cesium concentration/Target initial cesium concentration Ratio $=1.030$} & \multicolumn{2}{|c|}{$\mathrm{T}_{\mathrm{i}}=459$} \\
\hline \multicolumn{7}{|c|}{3 M Sodium Carbonate } \\
\hline \multicolumn{5}{|c|}{ Initial cesium concentration/Target initial cesium concentration Ratio $=1.031$} & \multicolumn{2}{|c|}{$\mathrm{T}_{\mathrm{i}}=458$} \\
\hline \multicolumn{7}{|c|}{3 M Sodium Hydroxide } \\
\hline \multicolumn{5}{|c|}{ Initial cesium concentration/Target initial cesium concentration Ratio $=0.994$} & \multicolumn{2}{|c|}{$\mathrm{T}_{\mathrm{i}}=459$} \\
\hline
\end{tabular}


Table 5. What-If Scenarios for Initial Cesium Concentration (Sorption Equilibrium Screening Test Set 2).

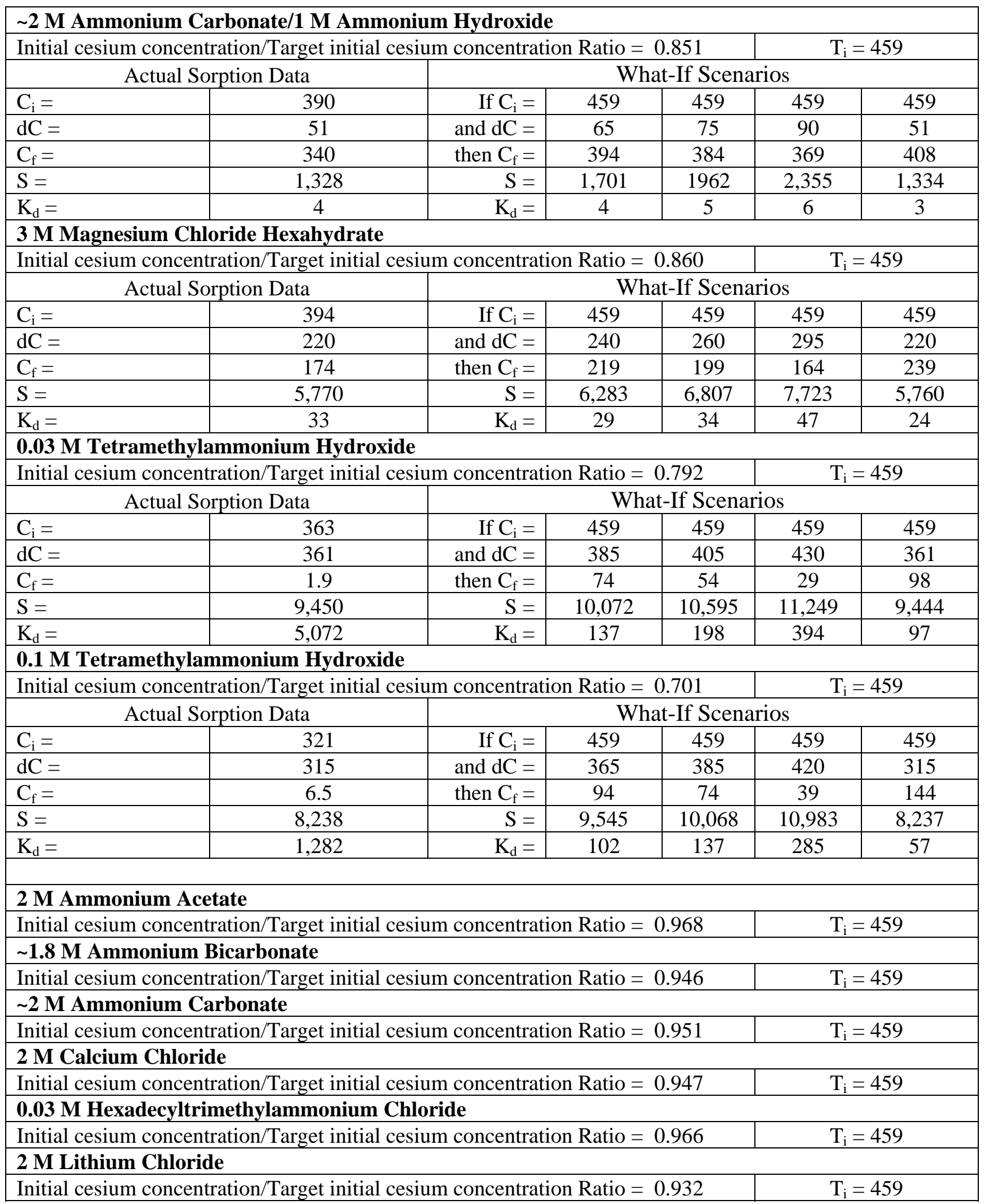


Table 5 Cont'd. What-If Scenarios for Initial Cesium Concentration (Sorption Equilibrium Screening Test - Set 2).

\begin{tabular}{|l|c|}
\hline$\sim 2.7$ M Lithium Hydroxide \\
\hline Initial cesium concentration/Target initial cesium concentration Ratio $=0.913$ & $\mathrm{~T}_{\mathrm{i}}=459$ \\
\hline 1.8 M Lithium Sulfate & $\mathrm{T}_{\mathrm{i}}=459$ \\
\hline Initial cesium concentration/Target initial cesium concentration Ratio $=0.935$ & $\mathrm{~T}_{\mathrm{i}}=459$ \\
\hline 1.8 M Magnesium Sulfate & $\mathrm{T}_{\mathrm{i}}=459$ \\
\hline Initial cesium concentration/Target initial cesium concentration Ratio $=0.947$ & \\
\hline$\sim 1.7$ M Potassium Bicarbonate \\
\hline Initial cesium concentration/Target initial cesium concentration Ratio $=0.979$ \\
\hline 0.75 M Sodium Bicarbonate \\
\hline Initial cesium concentration/Target initial cesium concentration Ratio $=0.960$ & $\mathrm{~T}_{\mathrm{i}}=459$ \\
\hline
\end{tabular}

Table 6. What-If Scenarios for Initial Cesium Concentration (Sorption Equilibrium Screening Test Set 3).

\begin{tabular}{|c|c|}
\hline \multicolumn{2}{|l|}{2 M Ammonium Acetate/1.5 M Ammonium Hydroxide } \\
\hline Initial cesium concentration/Target initial cesium concentration Ratio = 0.899 & $\mathrm{~T}_{\mathrm{i}}=459$ \\
\hline \multicolumn{2}{|l|}{ 1.8 M Ammonium Bicarbonate/1 M Ammonium Hydroxide } \\
\hline Initial cesium concentration/Target initial cesium concentration Ratio = 0.002 & $\mathrm{~T}_{\mathrm{i}}=459$ \\
\hline \multicolumn{2}{|l|}{ 0.05 M Hexadecyltrimethylammonium Chloride } \\
\hline Initial Cs concentration/Target Initial Cs concentration Ratio $=0.954$ & $\mathrm{~T}_{\mathrm{i}}=459$ \\
\hline \multicolumn{2}{|l|}{2 M Lithium Chloride/ 1 M Lithium Hydroxide } \\
\hline Initial cesium concentration/Target initial cesium concentration Ratio $=0.927$ & $\mathrm{~T}_{\mathrm{i}}=459$ \\
\hline \multicolumn{2}{|l|}{ 1.8 M Lithium Sulfate/ 0.5 M Lithium Hydroxide } \\
\hline Initial cesium concentration/Target initial cesium concentration Ratio $=0.983$ & $\mathrm{~T}_{\mathrm{i}}=459$ \\
\hline \multicolumn{2}{|l|}{ 1.7 M Potassium Bicarbonate/0.5 M Potassium Hydroxide } \\
\hline Initial cesium concentration/Target initial cesium concentration Ratio = 0.888 & $\mathrm{~T}_{\mathrm{i}}=459$ \\
\hline \multicolumn{2}{|l|}{3 M Potassium Carbonate/0.5 M Potassium Hydroxide } \\
\hline Initial cesium concentration/Target initial cesium concentration Ratio = 0.971 & $\mathrm{~T}_{\mathrm{i}}=459$ \\
\hline \multicolumn{2}{|l|}{ 0.75 M Sodium Bicarbonate/0.5 M Sodium Hydroxide } \\
\hline Initial cesium concentration/Target initial cesium concentration Ratio = 0.999 & $\mathrm{~T}_{\mathrm{i}}=459$ \\
\hline \multicolumn{2}{|l|}{ 1.5 M Sodium Carbonate/0.5 M Sodium Hydroxide } \\
\hline Initial cesium concentration/Target initial cesium concentration Ratio = 0.956 & $\mathrm{~T}_{\mathrm{i}}=459$ \\
\hline \multicolumn{2}{|l|}{ 0.03 M Tetrabutylphosphonium Hydroxide } \\
\hline Initial cesium concentration/Target initial cesium concentration Ratio = 0.968 & $\mathrm{~T}_{\mathrm{i}}=459$ \\
\hline \multicolumn{2}{|l|}{ 0.05 M Tetrabutylphosphonium Hydroxide } \\
\hline Initial cesium concentration/Target initial cesium concentration Ratio $=0.908$ & $\mathrm{~T}_{\mathrm{i}}=459$ \\
\hline \multicolumn{2}{|l|}{ 0.03 M Tetramethylammonium Chloride } \\
\hline Initial cesium concentration/Target initial cesium concentration Ratio = 0.901 & $\mathrm{~T}_{\mathrm{i}}=459$ \\
\hline \multicolumn{2}{|l|}{ 0.03 M Tetramethylammonium Chloride/0.03 M Tetramethylammonium Hydroxide } \\
\hline Initial cesium concentration/Target initial cesium concentration Ratio $=0.953$ & $\mathrm{~T}_{\mathrm{i}}=459$ \\
\hline \multicolumn{2}{|l|}{$\begin{array}{l}\text { 0.03 M Tetramethylphosphonium Bromide } \\
\text { Initial cesium concentration/Target initial cesiu }\end{array}$} \\
\hline Initial cesium concentration/Target initial cesi & \\
\hline
\end{tabular}

Table 7. What-If Scenarios for Initial Cesium Concentration (Sorption Kinetics Test).

\begin{tabular}{|l|c|}
\hline$\sim 2$ M Ammonium Carbonate \\
\hline Initial cesium concentration/Target initial cesium concentration Ratio $=0.938$ & $\mathrm{~T}_{\mathrm{i}}=459$ \\
\hline Spiked Tank 2F Simulant & $\mathrm{T}_{\mathrm{i}}=458$ \\
\hline Initial cesium concentration/Target initial cesium concentration Ratio $=0.925$ & \\
\hline
\end{tabular}


Table 8. Ranking of Eluants from the Cesium Sorption Equilibrium Screening Tests (Sets 1, 2 \& 3).

\section{Eluant Solution}

$\sim 2$ M Ammonium Carbonate

$\sim 2$ M Ammonium Carbonate/1 M Ammonium Hydroxide

$\sim 1.8$ M Ammonium Bicarbonate

3 M Rubidium Carbonate

2 M Ammonium Acetate

2 M Ammonium Acetate/1.5 M Ammonium Hydroxide

1.8 M Ammonium Bicarbonate/1 M Ammonium Hydroxide

2 M Calcium Chloride

3 M Magnesium Chloride Hexahydrate

3 M Potassium Carbonate/0.5M Potassium Hydroxide

3 M Potassium Carbonate

$1.8 \mathrm{M}$ Lithium Sulfate

$2 \mathrm{M}$ Lithium Chloride

1.8 M Magnesium Sulfate

3 M Potassium Hydroxide

1.7 M Potassium Bicarbonate/0.5 M Potassium Hydroxide

0.05 M Hexadecyltrimethylammonium Chloride

0.03 M Hexadecyltrimethylammonium Chloride

$\sim 1.7$ M Potassium Bicarbonate

0.75 M Sodium Bicarbonate

$1 \mathrm{M}$ Tetramethylammonium Hydroxide

0.75 M Sodium Bicarbonate/0.5 M Sodium Hydroxide

0.03 M Tetramethylammonium Chloride/0.03 M

Tetramethylammonium Hydroxide

0.03 M Tetramethylphosphonium Bromide

1.8 M Lithium Sulfate/ 0.5 M Lithium Hydroxide

0.03 M Tetramethylammonium Chloride

1.5 M Sodium Carbonate

1 M Tetrabutylphosphonium Hydroxide

2 M Lithium Chloride/ 1 M Lithium Hydroxide

1.5 M Sodium Carbonate/0.5 M Sodium Hydroxide

0.1 M Tetramethylammonium Hydroxide

3 M Sodium Hydroxide

0.03 M Tetrabutylphosphonium Hydroxide

0.05 M Tetrabutylphosphonium Hydroxide

2.7 M Lithium Hydroxide

0.03 M Tetramethylammonium Hydroxide

\begin{tabular}{|c|c|c|c|}
\hline pH & $K_{d}, L / k g$ & Rank & Cesium Elution Potential \\
\hline 9 & 2.62 & 1 & High \\
\hline 9 & 3.92 & 2 & High (what-if scenario $\mathrm{K}_{\mathrm{d}}$ range is $4-6$ ) \\
\hline 9 & 5.37 & 3 & High \\
\hline 10.5 & 5.43 & 3 & High (what-if scenario $\mathrm{K}_{\mathrm{d}}$ range is 2-7) \\
\hline 7 & 7.59 & 5 & High \\
\hline 10 & 8.97 & 6 & High \\
\hline 9 & 12.0 & 7 & High \\
\hline 6 & $16.7 / 11.3 / 22.0$ & 8 & High \\
\hline 5 & 33.2 & 9 & High (what-if scenario $\mathrm{K}_{\mathrm{d}}$ range is 29-47) \\
\hline $11 / 14$ & $49.5 / 39.9 / 59.9$ & 10 & High \\
\hline $14 / 14$ & 57.1 & 11 & High \\
\hline 8 & 59.1 & 12 & High \\
\hline 6 & $75.0 / 54.3 / 95.8$ & 13 & High \\
\hline 7 & 78.1 & 14 & High \\
\hline 14 & 78.1 & 14 & High \\
\hline $9 / 10$ & 87.6/65.3/110 & 16 & High \\
\hline 7 & 198/160/237 & 17 & Moderate/low \\
\hline 7 & 212 & 18 & Low \\
\hline $9 / 11$ & 274 & 19 & Low \\
\hline 8 & 357 & 20 & Low \\
\hline 13 & 364 & 21 & Low/moderate based on the what-if scenario $K_{d}$ range of 105-249 \\
\hline 10 & 382 & 22 & Low \\
\hline 13 & 401 & 23 & Low \\
\hline 7 & 464 & 24 & Low \\
\hline 14 & 503 & 25 & Low \\
\hline 7 & $540 / 280 / 800$ & 26 & Low \\
\hline $14 / 14$ & 633 & 27 & Low \\
\hline 13 & 758 & 28 & Low/moderate based on the what-if scenario $K_{d}$ range of 133-394 \\
\hline 13 & 997 & 29 & Low \\
\hline 14 & 1,128 & 30 & Low \\
\hline 14 & 1,282 & 31 & Low/moderate based on the what-if scenario $K_{d}$ range of 102-285 \\
\hline 14 & 1,938 & 32 & Low \\
\hline 14 & 3,164 & 33 & Low \\
\hline 14 & 3,927 & 34 & Low \\
\hline 14 & 4,439 & 35 & Low \\
\hline 14 & 5,072 & 36 & Low/moderate based on the what-if-scenario $\mathrm{K}_{\mathrm{d}}$ range of $137-394$ \\
\hline
\end{tabular}

Page 19 of 22 


\subsection{CONCLUSIONS}

Out of the 36 non-acid eluants screened, nine stand out as the most promising. They are as follows in order of decreasing elution potential (based on lowest cesium sorption distribution coefficients).

$\sim 2$ M Ammonium carbonate

$2 \mathrm{M}$ Ammonium carbonate/1 $\mathrm{M}$ ammonium hydroxide

$\sim 1.8 \mathrm{M}$ Ammonium bicarbonate

3 M Rubidium carbonate

$2 \mathrm{M}$ Ammonium acetate

$2 \mathrm{M}$ Ammonium acetate/1.5 $\mathrm{M}$ ammonium hydroxide

1.8 M Ammonium bicarbonate/1 $\mathrm{M}$ ammonium hydroxide

2 M Calcium chloride

3 M Magnesium chloride hexahydrate

\subsection{PATH FORWARD}

Complete the next (last) phase of testing for this study using eluants down selected from the nine promising candidates mentioned in the last section. The selected eluants are ammonium carbonate, ammonium acetate, calcium acetate, magnesium acetate, nitric acid, and ammonium hydroxide.

Due to corrosion concerns, calcium chloride and magnesium chloride have been replaced with calcium acetate and magnesium acetate respectively. Nitric acid is the benchmark eluant. Ammonium hydroxide, as a stand-alone eluant, was not tested. However, the data seem to suggest it may be a viable candidate even though it is a weak base.

Ammonium bicarbonate is basically in the same chemical family as ammonium carbonate. Hence, its exclusion from the eluants selected for the next testing phase despite its high elution potential. Similarly, rubidium carbonate is not among the eluants selected. From operational standpoint, cesium-laden rubidium carbonate eluate from an ion exchange elution process will end up being stored at the tank farm prior to treatment through the WTP. Any potential cross-contamination of this eluate with an untreated cesium-containing tank waste implies the untreated waste will be cesium/rubidium-containing tank waste. Rubidium is a competitor to cesium in the SRF ion exchange loading process. As a result, less cesium will be removed for a given sRF column because rubidium will be removed as well. The same argument holds for potassium compound eluants.

The next testing phase seeks to confirm the elution ability from loaded resins of the selected eluants. It will involve the typical sorption or loading, caustic wash, water rinse, and elution via batch contact sorption and quasi column caustic wash, water rinse, and elution. 


\subsection{REFERENCES}

1. M. Thorson, "Basis of Recommendation for Use of Spherical Resorcinol Formaldehyde Resin as the Primary Cesium Ion Exchange Resin in the WTP," 24590-WTP-RPT-RT07-005, February 2008.

2. J. N. Appel and S. H. Finfrock, "Criticality Safety Evaluation for Hanford Tank Farms Facility,” RPP-7475, Rev. 4, CH2M HILL Hanford Group, Inc. and Flour Government Group, Inc., September 2008.

3. J. Jo, "Tank Farms Waste Transfer Compatibility Program," Washington River Protection Solutions LLC, HNF-SD-WM-OCD-0 15, Rev. 21, Table 3-2, May 2010.

4. D. S. Kosson, D. R. Gallay, I. L. Pegg, R. G. Wymer, and S. Krahn, "External Technical Review of System Planning for Low-Activity Waste Treatment at Hanford," November 2008.

5. K Adu-Wusu and F. M. Pennebaker, "Literature Review on Non-Acid Elution of Cesium from Resorcinol-Formaldehyde Resin in Small Column Ion Exchange Units," SRNLSTI-2009-00455, Rev. 0, August 2009.

6. K. Adu-Wusu and F. M. Pennebaker, "Task Technical and Quality Assurance Plan for Non-Acid Elution of Cesium from Resorcinol-Formaldehyde Resin,” SRNL-TR-200900314, Rev. 0, August 2009.

7. C. A. Nash and M. R. Duignan, "Real Waste Testing of Spherical Resorcinolformaldehyde Ion Exchange Resin,” SRNL-STI-2009-00594, Rev. 0, October 2009.

8. C. A. Nash and M. R. Duignan, "Characterization of Cycled Spherical ResorcinolFormaldehyde Ion Exchange Resin,” SRNL-STI-2009-00605, Rev. 0, February 2010.

9. "RPP Phase 2 RF Resin Experiments", WSRC-NB-2004-00160, opened October 11, 2004.

10. C. A. Nash and S. T. Isom, "Characterization of Spherical Resorcinol-Formaldehyde Resin Cesium Adsorption with Batch Contact Tests," Separation Science and Technology, 45: 12, 1822 -1827.

11. F. G. Smith, "Modeling of Ion-Exchange for Cesium Removal from Dissolved Saltcake in SRS Tanks 1-3, 37 and 41," WSRC-STI-2007-00315, Rev. 0, August 2007.

12. C. A. Nash, "Hanford RPP-WTP Alternate Resin Program - Protocol P1-RF: Spherical Resin Sampling from Containers, Resin Pretreatment, F-Factor, and Resin Loading to Column,” SRNL-RPP-2004-00058, Rev. 0, August 2004. 
13. D. D. Walker, "Hanford RPP-WTP Alt Resin Program - Protocol P2-RF: Ion Exchange Batch Contact Tests,” SRNL-RPP-2004-00055, Rev. 0, July 2004.

14. D. Bradbury and T. Swan, "Radioactive Waste Volume Reduction by Sequential Ion Exchange - Caesium Resin Regeneration," Proceedings of British Nuclear Energy Society International Conference, Water Chemistry of Nuclear Reactor Systems 2, Paper 28, Bournemouth, UK, October 14-17, 1980.

15. R. M. Wallace and R. B. Ferguson, "Development of an Improved Ion Exchange Process for Removing Cesium and Strontium From High-Level Radioactive Liquid Wastes," SRS, DP-MS-80-65, Rev. 1, November 1980.

16. W. B. Barton, L. A. Gale, and M. E. Johnson, "Sixteen Years of Cesium Recovery Processing at Hanford's B Plant,” Rockwell Hanford Operations.

17. W. E. Poling, "Cell 18 Ion Exchange Flowsheet,” Rockwell Hanford Operations, RHO-F7, January 1980.

18. J. K. Nelson, G. J. Alkire, and B. W. Mercer, "Inorganic Ion Exchange Separation of Cesium from Purex-Type High-Level Radioactive Wastes,” Ind. Eng. Chem. Process Des. Dev., 3, 143-148, 1964.

19. J. R. Wiley and R. M. Wallace, "Removal of Cesium from Savannah River Plant Waste Supernate,” SRS, DP-1388, July 1975.

20. J. R. Wiley, "Ion Exchange Decontamination of Alkaline Solutions of Nuclear Waste,” SRS, DP-MS-76-69, March 1977.

21. J. R. Wiley, “Decontamination of Alkaline Radioactive Waste by Ion Exchange,” Ind. Eng. Chem. Process Des. Dev., 17, 67-71, 1978.

22. C. A. Nash, M. R. Duignan and C. E. Duffey, "Batch, Kinetics, and Column Data from Spherical Resorcinol-Formaldehyde Resins,” WSRC-STI-2006-00071, Rev. 0, December 2006.

23. W. D. King, C. E. Duffey, S. H. Malene, "Determination of Cesium (Cs $\left.{ }^{+}\right)$Adsorption Kinetics and Equilibrium Isotherms from Hanford Waste Simulants using ResorcinolFormaldehyde Resins,” WSRC-TR-2003-00574, Rev. 0, March 2004. 